\title{
La modernización de Puerto Vallarta ¿Renovación urbana o turistificación asistida?
}

\author{
Maria de los Angeles Huízar Sanchéz* Jorge Luis López Ramos** \\ José Alfonso Baños Francia**** \\ Universidad de Guadalajara (México)
}

\begin{abstract}
Resumen: En los últimos años, las autoridades de Puerto Vallarta han emprendido un proceso de regeneración urbana que permite a los promotores inmobiliarios la construcción desmedida de departamentos con fines turísticos, como lo demuestra la situación que se vive actuamente en dos de los sitios más emblemáticos del destinos: La Zona Romántica y Marina Vallarta. El objetivo del trabajo consiste en analizar el proceso de turistificación que enfrenta la ciudad, producto del desarrollo inmbiliario que impulsa la transformación de la vivienda y el comercio en favor del turista. El estudio es de tipo mixto y recoge los discursos de modernización de la ciudad y la percepción en los residentes en los diarios locales; además cuantifica el número de comercios y vivienda turística en comparación con los comercios y vivienda útil para el residente, cuyos resultados dan cuenta del acelerado proceso de turistificación que enfrentan la ciudad.
\end{abstract}

Palabras Clave: Turismo; Urbanización; Gentrificación; Desarrollo inmobiliario; Puerto Vallarta.

\section{The modernization of Puerto Vallarta. Urban renewal or assisted touristification?}

Abstract: In recent years, the authorities of Puerto Vallarta have embarked on an urban regeneration process that allows real estate developers to excessively build apartments for tourism purposes, as evidence by the current situation in two of the iconic places in the destination: The Romantic Zone and Marina Vallarta. The objective of the work is to analyze the touristification process that the city faces as a result of real estate development and the transformation of housing and commerce in these areas. The study is of a mixed type and includes discourses about the modernization of the city and the perception of residents in local newspapers, the results of which show the accelerated process of touristification facing the city.

Keywords: Tourism; Urbanization; Gentrification; Real estate development; Puerto Vallarta.

\section{Introducción}

El pueblito típico de Puerto Vallarta que ofrece la publicidad a los turistas ha quedado en el pasado. Las pequeñas casas blancas con techos de teja roja que por mucho tiempo fueron la imagen urbana y el elemento distintivo de este destino turístico de sol y playa, se diluyen cada vez más entre los grandes edificios que trae consigo el proceso de modernización emprendido en la ciudad por sus dirigentes, quienes han aprovechado el discurso de la regeneración urbana, la verticalización y la compactación de las ciudades para brindar todas las facilidades a los desarrolladores inmobiliarios para modificar la ciudad a placer.

Los sitios de mayor valor para el turismo se han convertido en el objeto del deseo para los promotores inmobiliarios que ven en cada espacio una oportunidad para construir edificios de mayor altura cada vez para destinarlos a la residencia o alquiler turístico. Negocio que ha ganado rentabilidad debido al auge de las plataformas digitales que ofrecen hospedaje como Airbnb y Booking, cuya oferta ha crecido en forma exponencial en un destino carente de regulación.

\footnotetext{
* Universidad de Guadalajara (México); E-mail: angeles.huizar@cuc.udg.mx; https://orcid.org/0000-0002-8051-4241

* Universidad de Guadalajara (México); E-mail: prescripcion@hotmail.com; https://orcid.org/0000-0002-2290-7004

*** Universidad de Guadalajara (México); E-mail: jose.banos@academicos.cuc.udg.mx; https://orcid.org/0000-0003-4734-9368
} 
La competencia por la adquisición de propiedades por parte de los desarrolladores inmobiliarios está impulsando un proceso de gentrificación turística que Gotham (2005) citado por Segeur (2015, pág.21) define como "La transformación de un barrio de clase media, en un próspero y exclusivo enclave marcado por la proliferación de empresas de entretenimiento y lugares turísticos". Para Hiernaux y González (2014) este proceso transforma radicalmente el espacio urbano debido a la intervención de capital orientado al turismo y se convierte en el sitio de mayor conflicto entre residentes locales y turistas. En referencia a las zonas de costa, Segeur (2015) señala que las transformaciones que presentan los centros turísticos son producto de una estrategia público-privada para la reestructuración del proceso de gentrificación que se presenta como una estrategia de renovación urbana y se sustenta en el incremento de la demanda generada por el mercado turístico y el potencial económico otorgado al paisaje de playa.

De esta forma, la presión que ejercen las inversiones inmobiliarias turísticas sobre los residentes locales los obliga a considerar la venta de sus casas o negocios mediante ofertas que superan su valor comercial, mientras que otros ceden ante la inconformidad que les generan las modificaciones realizadas en su comunidad, como el hecho de que su casa quede atrapada entre edificios de gran altura, la obstrucción de la vista al mar o la saturación de turistas.

Así, los espacios de los residentes locales se transforman en sitios de segunda residencia o alquiler turístico y los comercios primordiales para la vida cotidiana se convierten en tiendas de artículos exclusivos para el turista, dando paso a la turistificación del espacio, como señalan Cabrerizo, Sequera y Bachiller (2016) en el caso del Centro histórico de Madrid, y Vives-Miró y Rullan (2017) en el caso del Centro histórico de Palma de Mallorca, a los que se suma Barcelona (Mas, 2014) entre otros, que presentan condiciones similares.

Da la impresión de que esta estrategia llegó a Puerto Vallarta y se manifiesta a través de la acelerada construcción de nuevos desarrollos inmobiliarios destinados a la vivienda turística, principalmente en la Zona Romántica que forma parte del Centro histórico del municipio y otras áreas de interés turístico como el Fraccionamiento Marina Vallarta y las colonias aledañas a la franja turística, provocando cambios la estructura socioeconómica y territorial del municipio.

Ante esta situación, la población residente en las colonias involucradas ha manifestado su inconformidad publicamente por la actitud permisiva y de complicidad de las autoridades responsables, quienes ante los cuestionamientos de la sociedad, solamente se limitan a responder que todo el proceso se está realizando con apego a las normas y atendiendo los pronunciamientos internacionales en materia de desarrollo urbano, así como para fortalecer la competitividad del destino turístico y aprovechar la llegada de inversión nacional y extranjera. Sin embargo, el municipio presenta importantes rezagos en los procesos de planeación, ya que, tras varios intentos fallidos de actualización de su plan de desarrollo urbano, continúa operando con el aprobado en 2006. Al respecto, Baños (2015) señala que el municipio sí cuenta con los instrumentos de política y planes para su crecimiento ordenado, pero el problema radica en la nula aplicación de los mismos, sobre todo, en lo que corresponde a las normas de edificación, ya que las autoridades responsables aprovechan las prerrogativas legales para modificar discrecionalmente lo establecido en los planes urbanos a favor de los intereses de los promotores de proyectos. Situación que se ha intensificado en los últimós años en las áreas con mayor demanda turística de la ciudad como la Zona Romántica, Marina Vallarta y recientemente el tradicional barrio de Versalles.

En virtud de lo anterior, el presente trabajo tiene como objetivo analizar el proceso de turistificación impulsado por los desarrolladores inmobiliarios, y justificado por las autoridades locales bajo el discurso de la modernidad de la ciudad en La Zona Romántica y Marina Vallarta, dos de las zonas más emblemáticas de Puerto Vallarta, a través de un método mixto, que permite recoger los discursos de las autoridades y residentes vertidos en los principales medios de información locales, además de cuantificar y clasificar los comercios y viviendas destinados al turismo en comparación con la vivienda y los comercios útiles para los residentes en las áreas seleccionadas.

Los resultados permiten corroborar el proceso de turistificación y gentrificación que experimenta principalmente La Zona Romántica, donde el espacio de vivienda permanente y los comercios destinados a satisfacer las necesidades de sus residentes se han reducido considerablemente, cediendo su espacio a los alojamientos turísticos y a los comercios enfocados en atender las necesidades de los turistas, mientras que las protestas de los vecinos se intensifican en la ciudad en contra de estas construcciones, aludiendo a la pérdida de identidad, el desplazamiento de los pobladores originales y las afectaciones a su calidad de vida, sin que se tenga una articulación robusta en estas expresiones sociales. 


\section{La idea de la modernidad}

El poeta francés Charles Baudelaire escribió en su ensayo "el pintor de la vida moderna" (publicado en 1863) sobre la moderndad, "es lo efímero, lo veloz, lo contingente; es una de las dos mitades del arte, mientras que la otra es lo eterno y los inmutable", esta definición, aunque poética destaca el hecho de que la modernidad se caracteriza por tanto cambio y fugacidad.

Marx por su lado, nos dejó una metáfora escrita durante la mitad del siglo XIX diciendo que "todo lo sólido se desvanece en el aire" esta frase la construye, no solo con el propósito de describir el desplome de la sociedad feudal y el nacimiento de la modernidad y de la sociedad capitalista, sino que lo hizo como una condición permamente del desarrollo de la historia.

Se puede cosiderar a la modernidad como un conjunto de procesos de tipo social e histórico, los cuales tuvieron lugar en Europa al comienzo del siglo XV, con esto se marcó el final de la llamada Edad Media y el comienzo del Renacimiento uno de los cambios mas profundos que vivió la sociedad de ese tiempo fue la del pensamiento, dando prioridad a la racionalidad y al pensamiento científico.

Berman (1982, pág.15) citado por Harvey (1990, pag.19) establece su idea de modernidad de la siguiente forma: «En la actualidad, hay una forma de la experiencia vital, experiencia del espacio y del tiempo, del propio ser y de los otros, de las posibilidades y riesgos de la vida, que es compartida por hombres y mujeres de todas partes del mundo" a este cuerpo de experiencias Berman lo llamó modernidad.

Y es que la idea de la modernidad ha transitado por diferentes épocas de la historia del mundo y con diversas conceptualizaciones sumamente complejas, debido a que en los diferentes intentos han procurado dar un orden a los diversos períodos del desarrollo de la humanidad, por ello es que es los diversos discursos sobre el tema de la modernización han buscado la reflexión sobre cómo la sociedad ha contemplado su propia evolución, transformación y expectativas, así como de su historia y vinculación con la naturaleza y el espacio (Ramírez, 2003).

Desde ese análisis histórico, Habermas (1985) citado por Ramírez (2003) establece que:

La palabra moderno en su forma latina modernus su utilizó por primera vez en el siglo $\mathrm{V}$ con el fin de distinguir el presente, que se había vuelto oficialmente cristiano, del pasado romano y pagano, el término moderno con un contenido diverso, expresa una y otra vez la conciencia de una época que se relaciona con el pasado, la antigüedad, a fin de considerarse así misma como el resultado de una transición de lo antiguo a lo nuevo (Habermas, 1985, citado por Ramírez, 2003, Pág. 17).

El concepto de modernidad ha jugado un papel fundamental en el desarrollo de la humanidad, ha generado cambios sociales profundos y permitido importantes avances tecnológicos, pero también efectos e impactos que, con el tiempo, propiciaron transformaciones que reconfiguraron a la sociedad y a las ciudades donde se desarrolla.

De acuerdo con Uriarte (2019) de la modernidad se desprendieron una serie de características distintivas que moldearon la etapa histórica en la que se desarrolló y sentaron las bases para nuevas etapas, de entre éstas características se destacan:

- La racionalidad, como eje del pensamiento moderno

- La subjetividad, como base de la racionalidad

- El Estado-nación, se delimitan estructuras político-territoriales similares a las actuales

- División de poderes, se crea en contraposición al gobierno feudal y se constituyen tres poderes en tres instituciones diferente, ejecutivo, legislativo y judicial.

- El descubrimiento de América, como antecedente de la modernidad

- El desarrollo urbano, La sociedad industrial requería una concentración de población, dado que el trabajo está organizado en fábricas, las ciudades se convirtieron en centros de producción, pero simultáneamente en los lugares de mayor consumo de bienes, servicios y energía

- La sociedad industrial, el cambio de una sociedad rural a una sociedad industrial (urbana) fue paulatino y a su vez trajo consigo una serie de características importantes: la división del trabajo, el desarrollo de fábricas y la inversión y fabricación de máquinas que remplazaron el trabajo manual.

Este último punto es un antecedente claro de las actuales innovaciones tecnológicas, las cuales generaron un significativo aumento de beneficios, los cuales no solo están vigentes hasta nuestros días, sino, que además han evolucionado en forma vertiginosa, desarrollando nuevos paradigmas en la modernización de las ciudades, así como de sus consecuentes efectos e impactos. 


\section{De la modernidad a la posmodernidad}

La denominada posmodernidad surge con el propósito de lograr una concepción distinta del binomio hombre-realidad, relación en donde la única constante son los continuos cambios, en esta relación el hombre llegó a la conclusión de que todo aquello que él consideraba moderno o nuevo en una determinada época, se volvía normal, anticuado e incluso obsoleto en cuestión de días (Jiménez, 2003).

Analizado desde esta perspectiva descrita por Jiménez (2003) la realidad se construye y reconstruye de forma continua, de la misma manera los nombres utilizados para nombrar lo real vivían un proceso de desgaste en su significado por lo que, con el fin de adecuarlas a una nueva realidad se reconstruyeron $\mathrm{y}$ atribuyeron nuevos nexos en su significado.

Un ejemplo de ello es el mencionado por Jeremy Rifkin (2000), él establece que conceptos como propiedad y mercados eran prácticamente sinónimos durante la toda la época del modernismo, de hecho, la economía capitalista se funda sobre la idea del intercambio de propiedad en el mercado. La palabra mercado apareció en el lenguaje inglés en el siglo XII, en plena época del modernismo, y este concepto hacia referencia a ese espacio físico establecido para que de manera precisa vendedores y compradores intercambiaran bienes y ganado (Rifkin, 2000).

Este concepto de mercado ha evolucionado de ser un espacio tangible de intercambio, compra y venta de productos durante el modernismo a ser un espacio intangible, virtual, durante el posmodernismo.

Uno de los mas influyentes pensadores del mundo contemporáneo, el filósofo y sociólogo polaco Zygmunt Bauman estableció la posmodernidad como la base de su teoría sobre lo líquido, donde señaló que la modernidad sólida era un esquema social en el cual se conservaba la forma y se perpetuaba en el tiempo, él decía "La sociedad es sólida porque en ella era posible aún, pese a la secularidad que la caracteriza establecer raíces ideológicas, espirituales, que generaban confianza de pertenencia, de identidades colectivas" por ello, este autor desarrolló una teoría llamada la posmodernidad líquida basada en la idea de que los cambios son líquidos, se transforman constantemente, fluyen, cambian y se mueven (Bauman, 2013, p17).

En su libro La cultura de la modernidad líquida, este autor señala que,

"las características de la llamada posmodernidad líquida tiene una directa relación con el escenario en que se mueve también la política y la subjetividad de las personas, podemos concentrarlas en la extrema reducción del espacio y el tiempo, la insatisfacción de grandes masas en todo el mundo, que adquiere diversas motivaciones acorde al nivel de desarrollo alcanzado en cada país y en la incertidumbre, rasgo esencial de una liquidez que ha perdido toda posibilidad de establecer raíces sólidas” (Bauman, 2013, pág.24).

Desde la perspectiva de lo urbano, el desarrollo de las ciudades se da bajo esta teoría de lo líquido, las ciudades, en la actualidad, se ven perturbadas por un crecimiento urbano masivo que provoca un caos social producto del daño a sus raíces, a sus historia y tradiciones, y en consecuencia la pérdida del imaginario colectivo de la identidad.

Sin duda el elemento más característico de las ciudades posmodernas que describe Bauman es la incertidumbre, el sociólogo condena que los seres humanos en la actualidad, viven inmersos en una incertidumbre permanente de una sociedad claramente afectada por el síndrome del consumismo, la competencia individual, el desecho incesante de los productos y la dependencia por lo nuevo que el mercado ofrece (Bauman, 2003).

El desarrollo de las tecnologías se ha convertido en un factor de suma importancia en el desarrollo de las ciudades posmodernas, en ellas la economía no se limita a ofertar sus productos en el mercado de forma tradicional, sino que ve en la red y en la cultura del acceso el futuro de la comercialización, las ventas y el mercadeo.

\section{La renovaciónn urbana como estrategia de modernización}

La renovación urbana figura entre las principales estategias de modernización por parte de la gestión pública de las ciudades y como parte integral de su desarrollo económico, social, territorial y político que tiene como fin incrementar su competitividad en un entorno globalizado.

Para Carrión y Hanley (2005) la regeneración urbana de las ciudades puede influir en diferentes ámbitos: en la política, como un instrumento de legitimidad para las autoridades locales y en lo 
económico resaltan la importancia de las inversiones municipales para atraer más inversión, que, en conjunto, tienen como fin el fortalecimiento estatal y la sostenibilidad económica.

Es por ello, que los dirigentes políticos proponen generar proyectos de intervención en las zonas de mayor interés de las ciudades para lograr el reconocimiento y la legitimación a través de dichas obras, pero en otros casos, el mercado establece sus propias reglas e impulsa proyectos de regeneración conforme a sus propios intereses, dando paso al empresarialismo urbano que Cuenya y Corral (2011) definen como una nueva modalidad de gobernanza, que han adoptado autoridades locales de tendencias políticas diversas, que de acuerdo Harvey (1989) (citado por Cuenya y Corral, 2011) opera a través de cuatro estrategias básicas: 1) La ventajas en la producción de mercancías y servicios, 2) La mejora de la posición competitiva, 3) La lucha para atraer funciones de control en las finanzas y, 4) La captación y redistribución de excedentes y flujos de ayudas.

A través de estas medidas el Estado reconfigura el espacio en las ciudades, orientando la renovación urbana y la inversión a determinados espacios para generar nuevas centralidades atractivas para la inversión. Al respecto, el trabajo de Smith (2012) sobre la gentrificación, establece que el lenguaje de la revitalización y mejoramiento adopta como premisa la carencia de vitalidad de los sitios donde es necesario intervenir. Situación que no siempre concuerda con la realidad, como en los casos de los barrios de Barcelona, el centro de París o incluso las áreas que ocupan este estudio, donde existe una población vital, que cuenta con su propio estilo de vida, en cuyos casos, lo que se pretende es sustituir las connotaciones clasistas negativas que acompañan al proceso de gentrificación mediante términos como modernización, mejoramiento o reciclaje de barrio (Smith, 2012).

De esta forma los proyectos de renovación urbana dan paso a lo que García (2018) denomina un modelo de ciudad negocio, donde el espacio se destina principalmente al comercio, orientado por la rentabilidad que puede generar, fortaleciendo la relación entre intereses público-privado que dejan de lado la ciudad y su sentido como espacio social y de residencia para el desarrollo de todas las actividades inherentes al ser humano.

\section{Las ciudades turísticas, víctimas de su propio éxito}

El constante crecimiento del turismo lo coloca como una de las actividades económicas más dinámicas en el mundo, convirtiéndolo en el motor de desarrollo para algunos países y en la fuente de intensos problemas para otros, que tras su éxito como destinos turísticos han visto rebasada su capacidad de acogida de turistas.

Ciudades como París, Venecia, Barcelona y Amsterdam, entre otras, que figuran como destinos turísticos imprescindibles en las guías de viajes, han empezado a sufrir los embates de la saturación turística y los efectos socioeconómicos y territoriales negativos asociados a esta actividad, entre los que destacan el incremento en la irritación de la población residente señalada como turismofobia, (Milano, 2018; Huete y Mantecón, 2018), condición que se presume está relacionada con los procesos de gentrificación que detonan las actividades inmobiliarias y de alquiler turístico, al abrir la competencia económica por el uso del espacio entre residentes locales y segundas residencias o alquileres vacacionales. Situación que generalmente gana el poder económico del visitante y culmina con el desplazamiento del residente local.

Con el predominio del turista se inicia un proceso de turistificación del espacio, ya que una vez que es expulsado el residente local, sucede lo mismo con los comercios y servicios que no son útiles para el residente temporal, como las escuelas, servicios de salud comunitario y papelerías, los cuáles son sustituidos por los servicios que demanda el turismo, como hospedaje, restaurantes, bares y centros recreativos que se adaptan a sus necesidades.

Ante esta situación, los dirigentes de ciudades como París, han señalado que los servicios de hospedaje turístico que promueven las plataformas digitales como Airbnb, la están convirtiendo en una "ciudad museo" (Rosas, 2018).

Por otra parte, ciudades como Amsterdam, que enfrentan una situación similar, se han visto en la necesidad de implementar medidas para restringir la incorporación de servicios de hospedaje y comercios destinados esencialmente al turismo en las áreas más afectadas por la concentración turística (Abad, 2015).

La situación que presentan las grandes ciudades turísticas son un importante referente para el análisis de los efectos negativos que puede generar el turismo, si no se lleva a cabo una gestión responsable del mismo, ya que si bien, puede ser una fuente de riqueza e impulsar el desarrollo, también puede ser el responsable de generar caos y conflictos a su paso. 
En Puerto Vallarta, el segundo destino turístico más importante de México, hace aproximadamente diez años, inició un proceso de regeneración urbana impulsado por las autoridades locales bajo el discurso de la modernización, evento que los desarrolladores inmobiliarios han aprovechado para violentar los instrumentos de planeación de la ciudad y transformar los inmuebles tradicionales en torres de departamentos, destinados principalmente a la vivienda y alquiler turístico, condición que está modificando la imagen de pueblito típico e impulsa un proceso de gentrificación y turistificación similar a los señalados en otras ciudades del mundo. Condición que es necesario analizar en la ciudad, a través de la transformación que experimenta la ciudad en algunos sitios de interés turístico, como La Zona Romántica y Marina Vallarta, donde se está generando un gran número de desarrollos inmobiliarios ante las protestas y la inconformidad de los residentes.

\section{Metodología}

El método para el desarrollo del presente trabajo se divide en dos fases. La primera consistió en identificar con base en la observación directa los espacios que presentan mayor incidencia en desarrollos inmobiliarios con fines turísticos, a través de revistas especializadas, así como los conflictos registados en los diarios locales debido a la competencia entre residentes, turistas, desarrolladores inmobiliarios y gobernantes por el uso y apropiación del espacio, así como las opiniones vertidas al respecto por los residentes.

Durante la segunda fase se realizó el análisis de usos de suelo de 19 manzanas de la Zona Romántica, por ser la que presenta mayor afectación debido a la construcción de nuevos desarrollos inmobiliarios, mediante un levantamiento y clasificación de 305 negocios comerciales, vivienda de residencia permanente y alquiler turístico, con el objetivo de identificar la proporción entre las residencias permanentes y las de alquiler turísticos, así como de los comercios útiles para la población local en comparación con aquellos enfocados en las necesidades del turista.

Con respecto a Marina Vallarta y su condición residencial - turística se optó por analizar los nuevos desarrollos inmobiliarios y los conflictos que enfrentan sus promotores y gobierno local con los residentes, empresarios hoteleros y turistas que ostentan propiedades en dicha zona, ante la expansión de la oferta turística inmobiliaria.

Los resultados dan cuenta del intenso proceso de gentrificación y turistificación que presenta La Zona Romántica, así como los primeros signos de dichos procesos en Marina Vallarta, los cuales amenazan con expandirse a otras colonias del municipio.

Los resultados permitieron identicar las transformaciones que presenta el municipio y los procesos de gentrificación y turistificación que afectan a las zonas de estudio.

\section{Puerto Vallarta: De pueblito típico a ciudad moderna}

A finales de la década de los cuarenta, empezaron a llegar a Puerto Vallarta los primeros visitantes, cuando éste era aún un pueblo tranquilo con calles empedradas y casitas típicas de color blanco con tejado rojo en las que se sustenta la identidad de sus pobladores. Su impresionante patrimonio natural constituye el principal atractivo que lo ha posicionado entre los sitios turísticos más reconocidos, sin embargo, su patrimonio construido, aunque es sencillo, le otorga esa característica de pueblito típico a la orilla del mar, que le distingue de otros destinos de sol y playa del país, y constituye el elemento que ha sustentado la marca y la publicidad turística por casi 70 años.

La primera etapa de desarrollo turístico, en la década de los cincuenta y principios de los sesenta, se caracterizó por el turismo residencial, ya que la mayoría eran extranjeros que alquilaban casas modestas y convivían con la población local, compartiendo sus costumbres y tradiciones, sin embargo, en poco tiempo empezaron a llegar extranjeros con mayor poder adquisitivo que construyeron sus casas de residencia temporal en la ribera norte del Río Cuale, en la zona denominada Gringo Gulch, que actualmente ocupa la colonia El Cerro (Munguía, 2003).

Con el apoyo de los tres niveles de gobierno, se dotó al municipio con la infraestructura y vías de comunicación necesarias para detonar su desarrollo turístico, hechos que se reflejaron tanto en el aumento de turistas, como en el crecimiento de negocios y servicios para su atención.

El acelerado crecimiento de la población a finales de la década de los sesenta contribuyó a que el 31 de mayo de 1968, Puerto Vallarta obtuviera el título de ciudad mediante el decreto no. 8366 del 
Congreso del estado, al alcanzar la cifra de 17,740 habitantes y 55,451visitantes en ese año. Número de pobladores que se duplicó en los siguientes dos años, y triplicó el número de turistas (Munguía, 2003). Posicionando al destino como el de mayor importancia en el Occidente del país, que en la década de los ochenta llegaría a su etapa de auge, convirtiendose en un importante atractor de inversión nacional y extranjera, que si bien, impusieron nuevas tendencias arquitectónicas en la construcción de hoteles y condominios (Baños \& Moran, s.f.), la zona del centro se mantuvo con sus características de pueblo típico que lo diferenciaban de otros destinos de sol y playa del país.

Sin embargo, los primeros años del siglo XXI trajeron a los dirigentes de Puerto Vallarta la inspiradora idea de la modernización de la ciudad, un discurso que acompañaría a los siguientes alcaldes municipales para justificar la autorización de licencias de construcción para edificios de gran altura, cambios de uso de suelo y de la fisonomía del destino, pero ninguno consideró acompañar los proyectos con la infraestructura necesaria para su adecuado funcionamiento, ni con estrategias que permitieran distribuir los beneficios económicos generados a otros espacios del municipio con mayor rezago. Fortaleciendo con ello, los señalamientos negativos por parte de la sociedad vallartense e incrementando la irritación de la población que recibe directamente los efectos negativos de los desarrollos autorizados.

De acuerdo con Romero (2007), Puerto Vallarta inició un "boom" inmobiliario en 2004, con la construcción de desarrollos como Bay View Grand con 290 departamentos, Grand Venetian con 300 departamentos y 47 villas y Molino de Agua con 10 torres de departamentos con 12 pisos cada una. Además de anunciar los próximos desarrollos como Ícon Vallarta y Villas de la Colina II. Así mismo, señala que el sector inmobiliario aportó más del 80 por ciento de la inversión privada en el Municipio, los cuales de 2004 al 2007 generaron 438 mil 211 millones de dólares en inversión, superando a la construcción en materia hotelera y turística que durante el mismo período generó 23 mil 523 millones de dólares.

Es importante resaltar que el Condominio Molino de Agua fue el primer edificio de gran altura que se autorizó en el centro de la ciudad, abriendo la puerta para la modificación de la imagen de pueblito típico sobre la que descansaba la publicidad y promoción del destino turístico desde su origen. Situación que no pasó desapercibida para los desarrolladores inmobiliarios que inmediatamente aprovecharon la oportunidad para generar nuevos proyectos de ese tipo en el centro de la ciudad, especialmente en la Zona Romántica.

Las primeras construcciones de gran altura en la zona hotelera norte y Marina Vallarta generaron malestar en diversos organismos empresariales y de representación social, los cuáles no dudaron en denunciar la situación ante las autoridades correspoondientes, aludiendo al incumplimiento de la legislación municipal. Hecho que dejó en evidencia que los permisos en cuestión fueron autorizados durante el período 2003-2006 a cargo del alcalde en turno, Gustavo González Villaseñor a los que se sumaron los desarrollos Nima Bay y Península (Proceso, 2007). Sin embargo, correspondió a la siguiente administración 2006-2009 a cargo de Javier Bravo Carbajal, dar respuesta a dichos reclamos, misma que se limitó a comprometer una revisión de la situación, convirtiéndose en un expectador más de los conflictos legales entre actores locales e inversionistas, que tras largos litigios concluyeron con resultados favorables para los últimos y sin responsabilidad alguna para quiénes los autorizaron. Hechos que al parecer alentaron el desarrollo de nuevos proyectos, a los que se sumó el siguiente presidente municipal (2009-2012) Salvador González Resendiz, quién apoyandose en el discurso de la modernización y la regeneración urbana de la ciudad decidió de manera unilateral y en medio de protestas, remodelar El Malecón, uno de los sitios más emblemáticos del municipio, cuyo costo de obra ascendió a 4.5 millones de dólares (Mochis Noticias, s.f), generando controversia con respecto a la prioridad de la obra, frente a las condiciones de marginación y carencias de infraestructura que persisten en un gran número de colonias del municipio.

Sin embargo, el mayor escándalo con respecto a los desarrollos inmobiliarios corresponde a la actual administración que encabeza Arturo Dávalos Peña, a quién se atribuye la autorización de un tercio de las licencias de construcción en la Zona Romántica durante su primer mandato correspondiente al período 2015-2018 (Vallarta independiente, 2017).

En la toma de protesta de su segundo mandato (2018-2021) el alcalde reelecto enunció las directrices que guiarán este segundo período, entre las que señaló: trabajar por una ciudad más justa y solidaria, con mejores servicios públicos, más programas sociales, turismo, empleos e inversiones y obras. En dicho evento, recurrió nuevamente al discurso de la modernización de Puerto Vallarta al señalar que,

\footnotetext{
"Hoy enfrentar los retos del presente implica la tarea de renovar, de desechar estructuras obsoletas, pero también reafirmar lo que tenemos pendiente y definir hacia dónde vamos. Es momento de hacer un Pacto por Vallarta, por amor a esta tierra, por verla crecer, modernizarse, innovar sin dejar de ser el paraíso de montaña, mar y sol que nos enorgullece" (González, 2018).
} 
Discurso que sustenta las modificaciones que presenta actualmente la ciudad, donde la tendencia de construcción vertical se ha concentrado en la Zona Romántica, desde donde se ha expandido a otras colonias de la ciudad como Marina Vallarta donde ya empezaron las protestas ciudadanas por las construcciones que rebasan los niveles permitidos, sin embargo, las autoridades implicadas continúan justificando su actuación con el discurso de la ciudad compacta propuesto en la Nueva Agenda Urbana de la Organización de las Naciones Unidas (ONU-HABITAT) sin considerar las características sociodemográficas y de crecimiento poblacional en una ciudad con 275,640 habitantes (INEGI, 2015) que aún tiene colonias sin consolidar.

\section{La Zona Romántica: De la modernización a la turistización}

La colonia Emiliano Zapata es una de las más antiguas de la ciudad y lugar de residencia de los primeros pobladores de la misma. Esta constituye la mayor parte de la denominada Zona Romántica, un espacio que se distingue por ser el sitio predilecto de la comunidad LGBT que reside y visita el destino turístico, donde se ha generado una amplia gama de servicios turísticos enfocados en este segmento, que se caracteriza por un mayor poder adquisitivo y estancias más prolongadas (Huízar, Baños y López, 2018).

Su cercanía al centro la convierte en uno de los sitios con mayor demanda de hospedaje, situación que ha detonado el interés de los desarrolladores inmobiliarios por construir más espacios para este fin. Sin embargo, la escasez de terrenos disponibles genera presión sobre los espacios públicos y privados, de los cuáles, muchos han cedido ante las cuantiosas ofertas económicas que han permitido el incremento desmedido de desarrollos inmobiliarios de gran altura en toda la zona, destinados a la residencia y alquiler turístico (Imagen 1).

\section{Imagen 1: Desarrollos inmobiliarios concluidos en la Zona Romántica.}

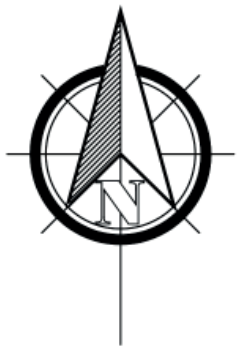

(1) RINCÓN DE ALMAS

(2) THE PARK

(3) PAVILION

(4) LOFT 268

(5) ZENITH

(6) NAYRI LIFE \& SPA

(7) PACIFICA

(8) OCEANA

(9) V399

(10) PIER 57

(11) 105 SAIL VIEW

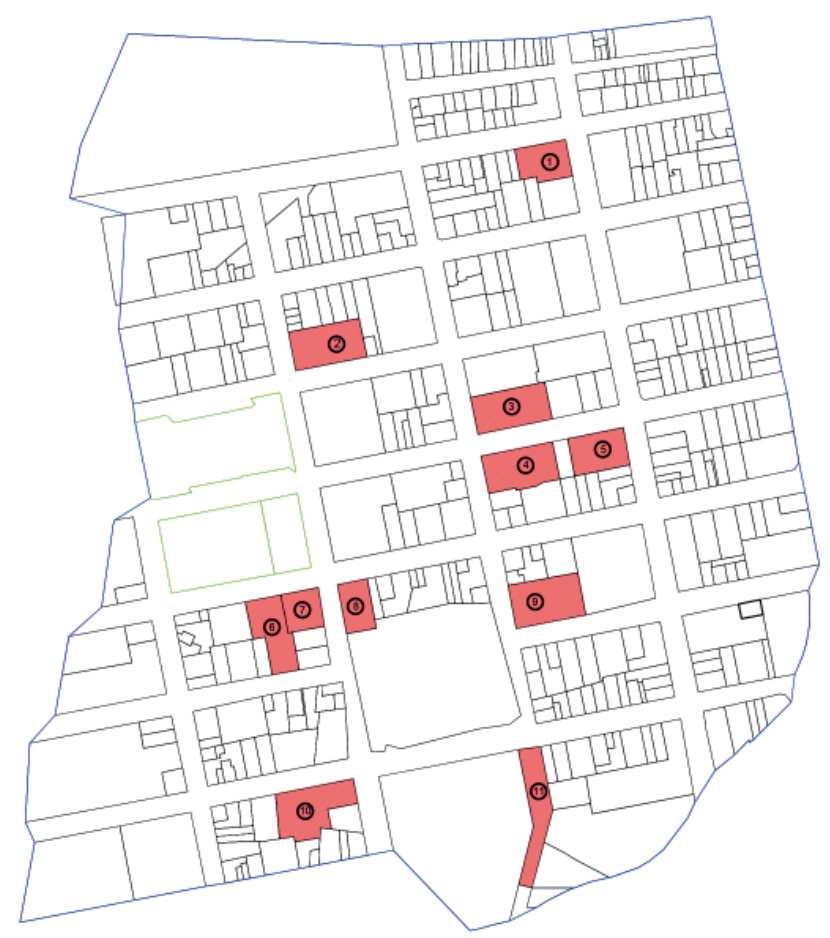

Fuente: Autor. 
La dispersión de los desarrollos inmobiliarios está contribuyendo a ampliar la influencia de la zona turística al resto de la colonia, e impulsando un proceso de turistización del espacio en cuestión, con servicios enfocados en atender las necesidades de los turistas, como lo muestra el análisis de usos de suelo de 19 manzanas de la Zona Romántica con 305 espacios comerciales, en la cuáles se localizan 38 conjuntos de departamentos turísticos, 33 restaurantes, 24 bares, 24 tiendas de artesanías y souvenirs, 15 establecimientos de spa y masajes, 15 boutiques, 14 galerías de arte, 11 joyerías y 10 estéticas, a los que se suman gimnasios e inmobiliarias, entre otros servicios para el turista.

En contraste, solamente se puede localizar en ese conjunto de manzanas 75 viviendas residenciales de uno y dos niveles, en las que destaca el uso mixto, con residencia en la planta alta y local comercial en la planta baja. Igual situación se presenta con los comercios dirigidos a los residentes, entre los que aún se puede contar una carnicería, una tortillería, una ferretería y dos tiendas de abarrotes, entre otros.

Los resultados muestran que aproximadamente el 70\% de la actividad comercial de la Zona Romántica se dirige al consumo del turista, situación que refleja importantes avances en el proceso de turistización de dicha zona.

Las condiciones que prevalecen en la Zona Romántica justifican la oleada de protestas por parte de los residentes, empresarios locales y asociaciones civiles, que una vez más presencian la destrucción de un espacio que sustenta la identidad e imagen del destino turístico debido a la vorácidad de los desarrolladores inmobiliarios y a la presunta complicidad de las autoridades municipales (Imagen 2)

\section{Imagen 2: Transformación de la Zona Romántica por los Desarrollos Inmobiliarios}

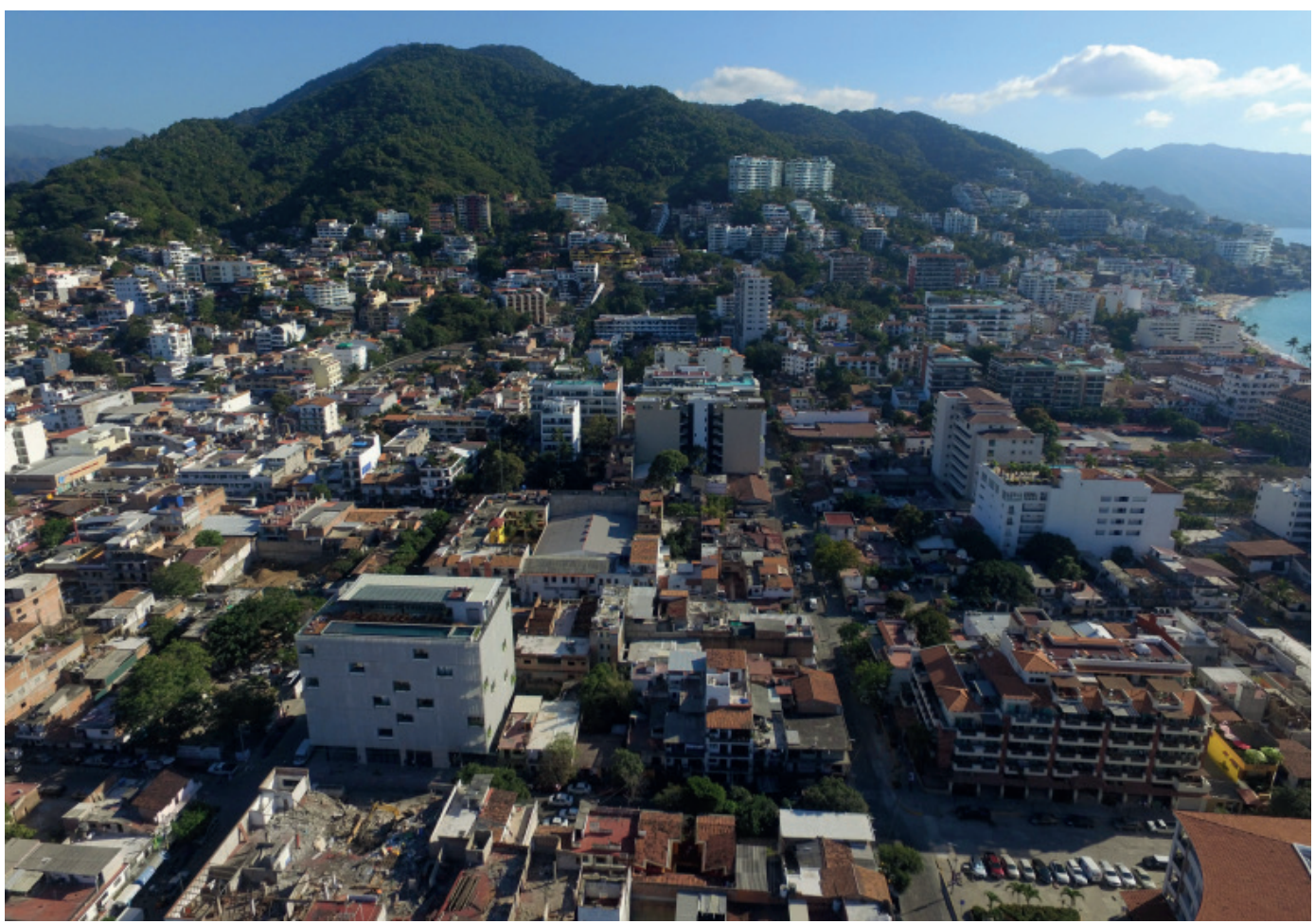

Fuente: Autor.

No obstante y más allá de las cuestiones simbólicas, los excesos en la urbanización de esa zona amenzan con colapsar una infrestructura de drenaje y agua potable que tiene más de cuarenta años y no esta diseñada para soportar el gran número de departamentos proyectados, de acuerdo con el titular del Servicio de Agua Potable y Alcantarillado (SEAPAL) (Vallarta Independiente, 2019), misma condición que se previó con respecto a la movilidad en la zona desde 2010 en las líneas de acción para 
el ordenamiento turístico del Centro histórico de Puerto Vallarta, Jalisco, generadas por EURA S.C. (2010) en cuya problemática estipulan que "Las pendientes de terreno en esta zona y las secciones viales reducidas demandan soluciones a los estacionamientos no resueltos por los desarrollos hoteleros y condominales de altas densidades" a los que proximamente se sumarán los nuevos desarrollos que se encuentran en proceso de construcción. Cuestiones que al parecer no fueron consideradas en el proceso de renovación urbana de ésta zona de la ciudad y que requieren de atención inmediata frente a las fugas de aguas negras que ya se presentan en la zona (Vallarta independiente, 2017), sin que las autoridades ofrezcan soluciones para los problemas que se avecinan en esta localidad.

\section{Marina Vallarta}

Este fraccionamiento se ubica en la parte norte del municipio, su proceso de urbanización data de finales de los noventa. Este fraccionamiento cuenta con la infraestructura hotelera y de servicios más reciente, donde se combinan zonas habitacionales y segundas residencias con un campo de golf y una marina rodeada de condominios, restaurantes y comercios que la posicionan entre los sitios favoritos del turismo.

Las construcciones de mayor altura se ubicaron al frente de playa por parte de los hoteles y condominios. Para el resto del fraccionamiento se estableció una altura máxima de construcción de ocho niveles, sin embargo, en 2011 se aprobó la construccion de Nima Bay, un proyecto con 145 departamentos, repartidos en siete torres de 10 pisos, situación que ameritó el señalamiento por parte del director del aeropuerto, debido a su cercanía con éste espacio de ascenso y descenso de aviones, así como de los ciudadanos residentes en ese fraccionamiento, que, pese a sus protestas, no fueron considerados al momento de otorgar la autorización.

En 2017 se presentó la misma situación, debido a la aprobación de nuevos desarrollos inmobiliarios en el fraccionamiento, los cuales consideran 12 pisos. Circunstancia que llevó a los empresarios y residentes a realizar el 21 de septiembre de 2018 una manifestación en protesta por el incumplimiento del reglamento y la falta de atención de las autoridades municipales que, haciendo caso omiso de sus demandas, permitieron continuar con el ese proyecto y otorgar más licencias para este tipo de proyectos, que actualmente se encuentran en construcción.

La ratificación de la presente administración para un segundo período de tres años, señala que la tendencia de construcciones verticales continuará expandiéndose por toda la ciudad, como sucede actualmente con la colonia Versalles, donde el proceso de construcción de edificios se intensifica, impulsando un proceso similar al de la Zona Romántica, donde ya se advierten los primeros signos de gentrificación y turistificación. Así como el Pitillal, donde se construye actualmente el edificio de Bay View Pitillal y el desarrollo denominado Entorno S sobre la avenida México.

Ante este panorama, los vecinos de otras colonias se preparan para defenderse de la inminente incersión de este tipo de proyectos en sus espacios de residencia.

\section{Conclusiones}

La renovación urbana como estrategia de modernización se ha convertido en un elemento esencial de los proyectos de las ciudades a nivel global, cuyo objetivo es brindar a los residentes y visitantes una imagen moderna y más competitiva de la ciudad. Discurso que los gobiernos locales han adoptado para promover un desarrollo inmobiliario que se apega más a las necesidades del mercado y de los inversionistas inmobiliarios que a las necesidades de los ciudadanos.

En los últimos años, Puerto Vallarta enfrenta un proceso de renovación urbana promovido por sus dirigentes bajo el discurso de la modernización de la ciudad. Una modernización que únicamente se traduce en desarrollos inmobiliarios verticales que amenazan con destruir la imagen de pueblo típico, patrimonio en el que se sustenta la imagen del destino, pero ese proceso de renovación no atiende problemas esenciales, como la infraestructura de la red de drenaje y agua potable de la ciudad, misma que ya colapsó y generó importantes daños al Estero el Salado y contaminación del agua de la bahía.

La Zona Romántica es el espacio más afectado por la saturación de construcciones y ya experimenta los primeros signos de una sobrecarga inmobiliaria que promueve los procesos de gentrificación y turístificación del espacio al desplazar a la población local y sustituir los comercios esenciales para el residente por comercios destinados a satisfacer las necesidades del turista. Situación que contribuye 
a incrementar el nivel de irritación de la población local, que ante la indiferencia de las autoridades, recurre a las manifestaciones públicas como único recurso para hacerse escuchar, condición que puede desencadenar aspectos más serios, como la turismofobia desarrollada en las ciudades que se han visto rebasadas por el turismo y los problemas de masificación, gentrificación y turistización que genera si no se gestiona en forma adecuada.

Por otra parte, Marina Vallarta ya enfrenta la construcción de nuevos desarrollos inmobiliarios que violentan las normas de construcción establecidas y amenazan con la saturación de un espacio que se caracteriza por ofrecer condiciones de seguridad y tranquilidad, tanto a residentes como a visitantes, situación que ha generado una serie de protestas públicas contra la autoridad local, a la que se responsabiliza por otorgar permisos para la instalación de estos enormes desarrollos, que se presume impactarán en forma negativa en esa zona.

Por otro lado, no se capturó la plusvalía generada por el incremento de valor del suelo resultado del propio proceso de urbanización, dejándose pasar la oportunidad de financiar las obras de infraestructura necesarias, las cuales deberán ser pagadas con dinero público, asistiendo a una dinámica de acumulación por despojo. Ello acontece con la modificación discrecional de las normas de control urbanística obtenidas por medio de acuerdos informales entre funcionarios municipales y promotores inmobiliarios.

Ante este panorama, es importante que las autoridades locales consideren que un proyecto integral de ciudad, requiere de la participación de todos sus residentes para equilibrar las necesidades internas del orden local, con las externas que impone la globalización, donde la renovacion urbana considere las características de identidad, patrimonio y necesidades de sus pobladores, y no únicamente los caprichos o demandas del mercado.

\section{Bibliografía}

Abad, J.M. 19 de agosto de 2015. Airbnb quiere que Barcelona sea como Ámsterdam. El País, diario en línea. Recuperado de https://elpais.com/tecnologia/2015/08/04/actualidad/1438695849_391117.html.

Baños, A. 2015. Planes y políticas urbanas en Puerto Vallarta. Estudios Jalisciences (101), 30-41.

Baños, A. \& Moran, O. s.f. Historia de la Arquitectura de Puerto Vallarta - Parte III. Vallarta Real Estate Guide. Recuperado de https://vallartarealestateguide.com/es/historia-de-la-arquitectura-de-puerto-vallarta-parte-iii/.

Cabrerizo, C. Sequera, J. \& Bachiller, P. 2016. Entre la turistificación y los espacios de resisitencia en el centro de Madrid: Algunas claves para (re)pensar la ciudad turístca. Ecología política, (52), 78-82.

Carrión, F. \& Hanley, L. 2005. Regeneración y revitalización urbana en las Américas: hacia un Estado estable. Ecuador. FLACSO-WWICS-USAID.

Cuenya, B. \& Corral, M. 2011. Empresarialismo, economía del suelo y grandes proyectos urbanos: el modelo de Puerto Madero en Buenos Aires. EURE (Santiago), 37(111),25-45. Recuperado de https:// dx.doi.org/10.4067/S0250-71612011000200002.

Espinar, E. 2018. Gentrificación y Turistificación. Memòria del Treball de Fi de Grau. Facultat de Turisme. Universitat de les Illes Balears.

García, C. 2018. Lo llaman compartir hogar. Desmontando el bello cuento de Airbnb. Primera edición para kindle y Amazón.

Hiernaux, D. \& González, C.I. 2014. Turismo y gentrificación: pistas teóricas sobre una articulación. Revista de Geografía Norte Grande, 58, págs. 55-70.

Huete, R. \& Mantecón, A. 2018. El auge de la turismofobia ¿hipótesis de investigación o ruido ideológico? PASOS. Revista de Turismo y Patrimonio Cultural, 16 (1): 9-19. Recuperado de https://doi. org/10.25145/pasos.2018.16.001.

Huízar, M.A. Baños, J.A. \& López, J.L. 2018. El impacto del turismo LGBT en Puerto Vallarta. En Arnaiz, S.M \& Gómez, A.B. (coord.) El Turismo frente a los objetivos del desarrollo sustentable. México. Universidad de Guadalajara.

Jiménez, R. 2003. De la modernidad a la posmodernidad el tránsito necesario. Revista Ciencias de la Educación A o 3 • Vol. 2 • No 22 • Pag. 213 -224.

Mas, I. 2014. Bienvenidos a la fiesta: turistización planetaria y ciudades-espectáculo (y algo más). Ecología política, (47), 87-91.

Milano, C. 2018. Overtourism, malestar social y turismofobia. Un debate controvertido. PASOS. Revista de Turismo y Patrimonio Cultural, 16 (2): 551-564. Recuperado de https://doi.org/10.25145/j. pasos.2018.16.041. 
Mochis Noticias. s.f. Puerto Vallarta avanza con la renovación del Malecón. Recuperado de https:// mochisnoticias.com/puerto-vallarta-renovación-el-malecon/351502.

Munguía, C. 2003. Panorama histórico de Puerto Vallarta y la Bahía de Banderas. México. Universidad de Guadalajara.

Proceso 8 de julio de 2007. Una herencia peligrosa. Recuperado de https://www.proceso.com/93408/ una-herencia-peligrosa.

Ramírez, B.R. 2003. Modernidad, posmodernidad, globalización y territorio. Un recorrido por los campos de las teorías. México. Miguel Ángel Porrua - UAM.

Rifking, J. 2000. La era del acceso. La revolución de la nueva economía. Barcelona, España. Paidós.

Romero, D. 14 de mayo de 2007. Vive Puerto Vallarta "boom" inmobiliario. Periódico Mural. Recuperado de https://mural-guadalajara.vlex.com.mx/vid/vive-puerto-vallarta-boom-inmobiliario-80472368.

Rosas, P. 09 de octubre de 2018. París ya multa a los pisos de Airbnb y anima a unirse a Madrid y Barcelona. El Confidencial. Recuperado de https://www.elconfidencial.com/mudo/2018-10-09/airbnb-paris_1624385/.

Segeur, S. 2015. Nuevas urbanizaciones costeras, ¿gentrificación turística en bahía de Coquimbo? Revista de Urbanismo. 32, enero-junio. Págs. 18-31. Departamento de urbanismo, Universidad de Chile.

Smith, N. 2012. La nueva frontera urbana. Ciudad revanchista y gentrificación. Madrid. Traficantes de sueños.

Touraine, A. 2006. Crítica de la modernidad. México. Fondo de Cultura Económica.

Uriarte, J. 14 de agosto de 2019. Modernidad. Características.co. Recuperado de https://www.características.co/modernidad/.

Vallarta Independiente 20 de noviembre de 2017. 8 de las 24 contrucciones de la Zona Romántica fueron autorizadas en esta administración. Recuperado de https:/vallartaindependiete.com/2017/11/20/8-las-24-construcciones-la-zona-romantica-fueron-autorizadas-en-esta-administracion.

Vallarta Independiente 21 de noviembre de 2017. Se requieren de más de 150 mdp para evitar colapso de drenaje en Zona Romántica. Recuperado de https://vallartaindependiente.com/2017/11/21/se-requieren-mas-de-150-mdp-para-evitar-colapso-de-drenaje-en-zona-romantica/.

Vives-Miró, S. \& Rullan, O. 2017. Desposesión de vivienda por turistización?: Revalorización y desplazamientos en el Centro Histórico de Palma (Mallorca). Revista de Geografia Norte Grande, (67), 57-71. https://dx.doi.org/10.4067/S07/18-34022017000200004.

Zigmunt, B. 2013. La cultura en el mundo de la modernidad líquida. México. Fondo de Cultura Económica. 